\title{
Ethics of predictive testing for Huntington's chorea: the need for more information
}

\author{
D I O CRAUFURD, R HARRIS
}

\begin{abstract}
The finding of a genetically linked polymorphic DNA marker has made possible a predictive test for Huntington's chorea. This DNA probe has so far been used only for research and has technical limitations, but some workers now wish to apply it to clinical predictions. Those identified by the probe as being probable carriers of the Huntington's chorea gene would be exposed to uncertain psychological risks and social pressures. Ethical guidelines should be established, but these require greater knowledge of the potential benefits and hazards of this powerful new procedure. Controlled clinical trials are urgently needed.
\end{abstract}

\section{Predictive testing}

Huntington's chorea is a dominantly inherited, untreatable, progressive, and eventually lethal disease. The victim suffers extreme and protracted distress, but much of the burden arising from a diagnosis of Huntington's chorea falls on the relatives, who must cope with the mental and physical deterioration of the patients while coming to terms with the fact that they themselves and their children are now at high risk. ${ }^{1}$ The variable age of onset means that

\footnotetext{
Department of Medical Genetics, St Mary's Hospital, Manchester M13 0JH, and Department of Psychiatry, Manchester Royal Infirmary, Manchester M13 9WL

D I O CRAUFURD, MSC, MRCPSYCH, senior registrar

R HARRIS, MD, FRCP, professor of medical genetics

Correspondence to: Dr Craufurd.
}

many of those at risk will not know their genetic state until after they have completed their family, and non-carriers have to wait until late middle age before they can be reasonably certain of freedom from the threat of developing the disease themselves.

A predictive test to detect carriers of the Huntington's chorea gene before the onset of symptoms would offer several advantages to those at risk. Non-carriers would be freed from fear of developing the disease and the stigma attached to those at risk. They would no longer have the responsibility of deciding whether to abstain from procreation or seek abortions to break the chain of transmission. Efforts have been made for many years to find such a test. Previous candidates such as the levodopa provocation test proved unreliable, ${ }^{23}$ and debate to establish guidelines for predictive testing was called for before such testing became possible. ${ }^{45}$

The finding by Gusella and colleagues of a polymorphic DNA marker genetically linked to Huntington's chorea has now made possible a predictive test for people at risk, ${ }^{6}$ although this DNA probe (designated G8) has so far been used only for research. Indeed, the probe was distributed to laboratories on the understanding that investigators would not make use of it for clinical purposes without prior discussion with Dr Gusella. Much evidence confirming the linkage of G8 to Huntington's chorea has been accumulated since the finding of G8, and some clinicians now wish to use it for predictive testing. This has been controversial,,$^{7.9}$ and before the G8 probe is used clinically the ethics of predictive testing need to be clarified.

\section{Ethical issues}

In practice the predictive test is likely to give rise to ethical problems of three types. The first concerns the accuracy of the test and the possibility of inaccurate predictions. The second (and arguably most serious) concerns the possibility that some of those identified as probable gene carriers will be unable to cope with the burden of this knowledge. Finally, we must consider the possible misuse of information gained from predictive tests. 


\section{ACCURACY OF PREDICTIONS}

The information derived from predictive testing is used by those tested to make important decisions about their future lives, and it is therefore essential to know the risk that a prediction will prove incorrect. Two important questions about accuracy have to be asked. Firstly, is Huntington's chorea always caused by a mutation at a locus genetically linked to G8 or are there other forms of the disease for which results obtained with G8 would be misleading? Secondly, even if all Huntington's chorea is linked to G8 what is the likelihood of a recombination event separating the Huntington's chorea and G8 loci in a particular person and giving rise to false predictions?

A great deal of work has been done in many laboratories in different parts of the world to confirm the linkage between G8 and Huntington's chorea. Five families showing linkage between G8 and Huntington's chorea (lod scores in excess of 1.5) have been reported, ${ }^{610} 11$ and three more families have been documented in Cardiff. ${ }^{12} \mathrm{~A}$ further 16 large families were reported on orally at the meeting of the International Huntington's Association in Lille last year, but these data have not yet been published. As far as we are aware, no evidence for heterogeneity in Huntington's chorea has yet come to light, and Gusella and his colleagues indicated that about 20 such families would be sufficient to establish the absence of non-allelic heterogeneity. ${ }^{13}$ Studies to date, however, have concentrated on large kindreds, and the theoretical possibility cannot yet be excluded that heterogeneous forms of Huntington's chorea with reduced reproductive fitness will be found when smaller families are studied. Presumably if heterogeneity is found it will be possible to estimate the frequency (now likely to be small) of non-linked forms and incorporate this into risk predictions for people undergoing testing. It is disappointing that other useful genetic markers showing linkage to Huntington's chorea have not yet been found as these would improve the applicability of a predictive test: a larger proportion of those at risk could be helped, and additional markers would improve the accuracy of prediction. This would be especially true for probes that flank the Huntington's chorea locus, when it would be possible to recognise recombination events between the Huntington's chorea locus and the probes.

Given these limitations, is it necessary to insist that greater accuracy is necessary than is now available before $\mathrm{G} 8$ can be used in a predictive test? To answer this question it is important to recognise the distinction between prediction of risk in genetic counselling and presymptomatic diagnosis. The evidence to date suggests that the recombination fraction between $\mathbf{G 8}$ and the Huntington's chorea locus is unlikely to be much greater than 0.05 . In other words, predictions derived from the clinical use of the probe are likely to be wrong in about $5 \%$ of cases. This estimate may be too optimistic, and further errors may arise if in rare families Huntington's chorea is not linked to G8. A predictive test using G8 will still, however, permit estimations of risk that are considerably more precise than those currently derived from pedigree data alone. In Huntington's chorea every effort is already made to give the most accurate possible risk by combining pedigree information and the age of the person at risk. If it is accepted that these estimates of risk are useful then a technique that sharpens them presumably has advantages. There is here an analogy with the methods used to detect carriers of Duchenne muscular dystrophy, in which information from the pedigree structure, creatine kinase assays, and DNA probes is combined to give the best estimate of risk; these estimates, although imperfect, are used as the basis for profound decisions on reproduction including termination of pregnancy. Furthermore, the remaining small element of uncertainty has the merit of leaving a little hope for those predicted to have a very high risk.

Predictive testing promises clear benefits to those found not to be gene carriers, and these will be in a majority because testing will be sought only by those still at risk who are not already affected; these have a maximum risk of $50 \%$, but many will start from a $25 \%$ risk. The benefits to this majority, however, must be balanced against the possibility of harm to the remainder, who will be identified as probable carriers of Huntington's chorea; but these too will at least have a solid foundation on which to make decisions for the future, and this must also be taken into account.

\section{THE BURDEN OF KNOWLEDGE AND THE RISK OF SUICIDE}

Predictive testing for Huntington's chorea promises great benefits to those who prove not to be carriers, but it has been suggested that those shown to be carriers will be deprived of hope and will be at greatly increased risk of depression and suicide. ${ }^{14}$ The prevalence of psychiatric disorders is high in those who subsequently develop Huntington's chorea, ${ }^{15}{ }^{16}$ and there is an increased prevalence of suicide in some families at risk. ${ }^{17}$ In the United States the relative risk of a death being due to suicide is much higher in those with diagnosed or suspected Huntington's chorea than in the general population, ${ }^{18}$ although this finding was not confirmed by a recent study from Norway. ${ }^{19}$ Some of these studies were conducted before the advent of standardised methods of diagnosis and used subjects ascertained from mental hospital populations. Recent studies using unbiased ascertainment, however, established an increased prevalence of both conduct disorder and affective disorder in those at risk. ${ }^{2021}$ Whether this increase in psychopathology is due to the stress of being at risk or to a direct effect of the abnormal gene is not known. The prevalence of conduct disorder is highest in the offspring of parents with Huntington's chorea of early onset, suggesting that disruption of the early home environment may be an important aetiological factor, while affective disorder is not associated with early onset in the parent and may be a direct manifestation of the Huntington's chorea gene. ${ }^{20}$ The association between major affective disorder and risk of Huntington's chorea seems to be confined to certain families, ${ }^{21}$ supporting the suggestion of a primary genetic aetiology.

The case against predictive testing assumes that psychopathology in the population at risk is caused by knowledge of the risk of Huntington's chorea rather than a primary genetic cause, and it is further assumed that uncertainty is likely to be preferable to near certain knowledge of whether or not the disease will occur in due course. ${ }^{22}$ On the other hand it has been argued that early diagnosis would give carriers of the gene time to prepare emotionally and financially, thereby reducing the impact of the onset of symptoms when this occurs. ${ }^{23} 24$ Depending on which view is correct, predictive testing may be expected to increase or decrease the prevalence of suicide in this group. Pessimists argue that in the absence of a specific treatment the risks attached to predictive testing outweigh the benefits. On the other hand, there have been several surveys of populations at risk for Huntington's chorea to determine the probable demand for such a test. ${ }^{25} 26$ Between $58 \%$ and $80 \%$ of those surveyed said that they would welcome this development, although this was before G8 was found. Presumably those respondents who indicated a desire for predictive testing believed that the advantages of knowing would outweigh the disadvantages. Before predictive testing is made generally available it will be necessary to reconcile these conflicting views.

The conflict between honesty and the wish to reassure has always presented a clinical dilemma when the prognosis is poor and no treatment is available. The present climate of opinion favours honesty in dealing with requests from patients for information, ${ }^{27}$ and other diseases present problems that are relevant to Huntington's chorea. It has been suggested, for example, that patients with multiple sclerosis may benefit from being able to come to terms with their disease as soon as possible. ${ }^{28} 29$ Studies of surgical patients suggest that the amount of information sought preoperatively varies and that satisfactory psychological adjustment requires that disclosure of information is tailored to individual personality characteristics. ${ }^{30}$

Predictive testing for Huntington's chorea in asymptomatic subjects differs somewhat from communicating information about diagnosis to patients with cancer or multiple sclerosis. The onset of disease for a carrier of Huntington's chorea will usually be many years away, while a patient with cancer or multiple sclerosis may already know or suspect the diagnosis; moreover, a person's carrier state for Huntington's chorea also has important genetic implications for other family members, which is not generally the case for patients with cancer or multiple sclerosis. The recent concern about the acquired immune deficiency syndrome is perhaps particularly relevant because screening blood donors and organ donors for antibodies to the human immunodeficiency virus has led to the identification of a group of currently healthy seropositive people at high risk of developing the syndrome who are believed to confer risks on those close to them. These people face problems similar to those of carriers of the Huntington's chorea gene, and considerable psychological morbidity and social dysfunction have already been reported in them. ${ }^{31}$ It should be noted that these psychological problems have occurred after mass serological screening of blood donors and others, whereas predictive testing for Huntington's chorea would be limited to those who wish to be tested.

There is currently no empirical evidence that would allow a confident forecast of the psychological effects of predictive testing for Huntington's chorea.

\section{POSSIBLE MISUSE OF PREDICTIVE TESTING}

The result of a predictive test will inevitably be of interest to others besides the person at risk, and this may lead to conflict. For example, the spouse may wish to know while the person at risk does not. Conversely, when a parent is identified as a probable gene carrier this increases the risk for the children, who may not want this information. Sometimes predictive testing for one family member may be impossible unless another relative also agrees to be tested. In such cases pressure may be applied to persuade reluctant people to undergo the test. Furthermore, Caro wondered whether organisations such as pension funds, insurance companies, and prospective employers might have a right to demand such a test before entering into a contract with someone at risk. ${ }^{32} \mathrm{~A}$ similar problem may arise before marriage, either because of overt pressure or because of a sense of obligation on the part of the partner at risk. 


\section{Code of practice}

In view of these potential problems it is important to develop a code of practice for predictive testing (and this need will extend to other diseases in the future). For example, it might be held that predictive testing should not be offered to minors or used in cases in which it would determine the carrier state of a relative who did not wish to know. It has also been argued that insurance companies and others with a financial interest should be precluded by law from asking for information on carrier state. ${ }^{33}$ Other problems might be prevented by careful counselling before testing to ensure that the person understands the meaning and limitations of the results and by providing adequate support after testing to enable the person to adjust to the new knowledge. Skilled counselling would be essential to ensure as far as possible that testing took place only with the fully informed consent of the person concerned, free of any external pressures.

\section{Conclusion}

What is now required is a prospective study of the psychological and social consequences of predictive testing to evaluate the benefits and hazards and if possible to identify characteristics that help to forecast whether a person will be able to react constructively to the result. This would have the additional virtue of acting as a paradigm for similar problems that will surely arise after the application of new predictive methods to other and perhaps more common diseases.

A study would inevitably expose the subjects to some risks, but this does not give rise to any novel ethical problems, ${ }^{7}$ and it is for people to decide for themselves whether they wish to undergo predictive testing. Informed consent is essential, and it should be recognised that some people will adopt an altruistic attitude in seeking to protect their future progeny. Ethical approval should be given only to investigators who ensure that all subjects are provided with sufficient support and psychiatric supervision after testing so that it is possible to detect any psychopathology at an early stage and to intervene to minimise any further damage. Long term support for those identified as carriers of the gene will be required, and research designs will need to allow for this to continue long after data collection has been completed. In view of this need for long term support as well as the difficulty of obtaining a sample large enough to produce meaningful results, clinical trials of predictive testing will need to be carried out by those centres that already have experience with established genetic registers as a clinical and support service rather than simply as a research resource. These centres will already have identified subjects who have the necessary pedigree structure for predictive testing, and these subjects will be well known to the support staff attached to the register. A preexisting relationship with staff maintaining a genetic register coupled with formal psychiatric evaluations and close participation by general practitioners will offer the best prospect of detecting problems early enough to prevent serious consequences.

More accurate predictive tests for Huntington's chorea will probably become available, but this is not an argument for delay because more precise tests will leave less residual hope for those identified as carriers of the gene and we will be in even greater need of guidelines. Debate is clearly required to evolve guidelines for the clinical application of these new techniques, but this must be informed by the results of preliminary clinical trials. The time is ripe for these to begin.

We are grateful to Dr A P Read and Professor D P Goldberg for their helpful comments.

\section{References}

1 Korer J, Fitzsimmons JS. The effect of Huntington's chorea on family life. British fournal of Social Work 1985; 15:581-97.

Klawans HL, Paulson GW, Barbeau A. Predictive test for Huntington's chorea. Lancet 1970;ii:1185-6.

3 Klawans HL, Paulson GW, Ringel SP, Barbeau A. Use of L-dopa in the detection of presymptomatic Huntington's chorea. N Engl f Med 1972;286:1332-4

4 Anonymous. Predictive tests in Huntington's chorea [Editorial]. Br Med f 1978;i:528-9.

5 Harper PS. A genetic marker for Huntington's chorea. Br Med f 1983;287:1567-8.

6 Gusella JF, Wexler NS, Conneally PM, et al. A polymorphic DNA marker genetically linked to Huntington's disease. Nature 1983;306:234-8.

7 Watt DC, Lindenbaum RH, Jonasson JA, Edwards JH. Probes in Huntington's chorea. Nature 1986;320:21.

8 Gusella JF. Probes in Huntington's chorea. Nature 1986;320:21-2.
9 Frank N. Diagnosis of Huntington's chorea. Nature 1986;320:676

9 Frank N. Diagnosis of Huntington's chorea. Nature 1986;320:676.
10 Folstein SE, Phillips JA, Meyers DA, et al. Huntington's disease: two families with differing clinical features show linkage to the G8 probe. Science 1985;229:776-9.

11 Harper PS, Youngman S, Anderson MA, et al. Genetic linkage between Huntington's disease and the DNA polymorphism G8 in south Wales families. $\mathcal{F}$ Med Genet 1985;22:447-50.

12 Youngman S, Sarfarazi M, Quarrell OWJ, et al. Studies of a DNA marker (G8) genetically linked to Huntington's disease in British families. Hum Genet (in press).

13 Wexler NS, Conneally PM, Houseman D, Gusella JF. A DNA polymorphism for Huntington's disease marks the future. Arch Neurol 1985;42:20-4.

14 Stevens DL. Tests for Huntington's chorea. N Engl f Med 1971;285:413-4.

15 Dewhurst K, Oliver JE, McKnight AL. Socio-psychiatric consequence of Huntington's disease. Brf Psychiatry 1970;116:255-8.

16 Bolt JMW. Huntington's chorea in the west of Scotland. Br F Psychiatry 1970;116:259-70.

17 Minski L, Guttmann E. Huntington's chorea: a study of thirty four families. Journal of Mental Science 1938;84:21-96.

18 Schoenfeld $M$, Myers RH, Cupples LA, et al. Increased rate of suicide among patients with Huntington's disease. I Neurol Neurosurg Psychiatry 1984;47:1283-7.

19 Saugstad L, Odegard O. Huntington's chorea in Norway. Psychol Med 1986;16:39-48.

20 Folstein SE, Franz ML, Jensen BA, et al. Conduct disorder and affective disorder among the offspring of patients with Huntington's disease. Psychol Med 1983;13:45-52.

21 Folstein SE, Abbott MH, Chase GA, et al. The association of affective disorder with Huntington's disease in a case series and in families. Psychol Med 1983;13:537-42.

22 Fahn S. Levodopa provocative test for Huntington's disease. N Engl J Med 1980;303;884.

23 Bates $M$. Ethics of a provocative test for Huntington's disease. N Engl f Med 1981;304:175-6.

24 Thomas S. Ethics of a predictive test for Huntington's chorea. Br $\mathcal{F}$ Med 1982;284:1383-5.

25 Tyler A, Harper PS. Attitudes of subjects at risk and their relatives towards genetic counselling in Huntington's chorea. F Med Genet 1983;20:179-88.

26 Barette J, Marsden CD. Attitudes of families to some aspects of Huntington's chorea. Psychol Med 1979;9:327-36.

27 Anonymous. On telling dying patients the truth [Editorial]. F Med Ethics 1982;8:115-6.

28 Burnfield A, Burnfield P. Common psychological problems in multiple sclerosis. Br Med $\mathcal{F}$ 1978;i:1193-4.

29 Elian M, Dean G. Need for and use of social and health services by multiple sclerosis patients living at home in England. Lancet 1983;ii: 1091-3.

30 Miller SM, Mangan CE. Interacting effects of information and coping style in adapting to gynecologic stress: should the doctor tell all? f Pers Soc Psychol 1983;45:223-36.

31 Miller D, Jeffries DJ, Green J, Harris JRW, Pinching AJ. HTLV-III: should testing ever be routine? BrMed f 1986;292:941-3.

32 Caro A. Huntington's chorea. The Physician 1984 July: $18-9$.

33 Berg K, Fletcher J. Ethical and legal aspects of predictive testing. Lancet 1986;i: 1043.

(Accepted 30 June 1986)
What is the present attitude on the efficacy of lithium as treatment for manic depression and depressions of other aetiology?

The use of lithium salts in the management of mood disorders has been one of the most rewarding therapeutic strategies in psychiatry. There is overwhelming evidence for their efficacy, and the morbidity of recurrent affective disorders has been substantially reduced. ${ }^{1}$ In acute mania lithium is as effective as neuroleptic medication (phenothiazines and butyrophenones) and has the advantage that patients do not experience the "straight jacket" effect associated with neuroleptic medication. Moreover, lithium is less likely to cause the serious unwanted effect of tardive dyskinesia associated with the long term use of neuroleptic medication. As an antidepressant it is probably less effective than conventional antidepressants (tricyclics and monoamine-oxidase inhibitors) but is an effective adjunct to these antidepressants in patients with resistant depressions. ${ }^{2}$ There is a clear trend for patients with bipolar depressions - that is, acute depression in a patient who had suffered a previous episode of mania-to have a more favourable response than patients with depression without such a history. Lithium salts, however, have been mainly used as prophylactic treatment in the management of bipolar (depression alternating with mania) and unipolar (recurrent depression) illness. In unipolar patients it is particularly effective in those with an endogenous profile of symptoms, patients with a positive family history of depression, and those who had shown less personality disturbance before the onset of their first episode of illness. Patients with unipolar illness with a non-endogenous profile of symptoms (neurotic depression) may benefit from lithium if it was combined with psychological treatment, particularly cognitive therapy.-M T ABOU-SALEH, senior lecturer in psychiatry, Liverpool.

I Abou-Saleh MT, Ghodse AH. Lithium in medical practice. Pharmaceutical fournal 1983;231:6182 Himmelhock JM, Detre T, Kupfer DJ, Swartzburg M, Byck R. Treatment of previously intractable depressions with tranylcypromine and lithium. $\mathcal{J}$ Nerv Ment $D$ is 1972;155:216-20. 